\title{
INEXPENSIVE, ARDUINO-BASED DEVICE FOR ON-LINE, AUTOMATIC, REAL-TIME MEASUREMENT OF METHANE COMPOSITION AND BIOGAS FLOWRATE FROM ANAEROBIC DIGESTERS
}

\author{
Shunchang Yang $^{1}$, Spyros Svoronos ${ }^{1}$, and Pratap Pullammanappallil ${ }^{1}$ \\ ${ }^{1}$ University of Florida
}

September 28, 2020

\begin{abstract}
Anaerobic digestion is widely used for waste treatment and for biofuel production in the form of biogas from dedicated energy crops. Proper operation and control of anaerobic digesters require knowledge of biogas flow rate and methane composition of biogas. Methane content of biogas from an anaerobic digester was measured on-line by modifying an off-line measurement device, previously constructed by the authors, that uses a hydrocarbon sensor (MQ-4) and a pressure/temperature/humidity sensor (BME-280) integrated with an Arduino Uno. This modified on-line sensor was programmed to automatically measure methane composition by self-regulated introducing biogas sample and evacuating the device. It also equipped with a function of biogas flow chamber which could calculate the cumulative biogas production over a time interval. Methane composition (v/v) could be measured every three hours. Measurements made by this device agreed within an average absolute difference of 0.81 $\pm 0.58 \%$ with measurements by a gas chromatograph equipped with a thermal conductivity detector. The volumetric flow rate was directly expressed on a moisture-free basis at standard temperature and pressure. The total cost of this device was under US $\$ 140$. For an additional US $\$ 7$, the device can be upgraded with an LED display that toggles between composition and flow rate.
\end{abstract}

\section{Keywords:}

Biogas; Anaerobic digestion; On-line methane composition; Arduino Uno; Renewable Natural Gas

\section{INTRODUCTION}

Anaerobic digestion is a biochemical process, mediated by a diverse population of syntrophic microorganisms belonging to domains of Bacteria and Archaea. The process mineralizes organic compounds to biogas under anaerobic conditions. Moisture free biogas is primarily a mixture of methane and carbon dioxide, typically containing 50-70\% methane by volume. Anaerobic digestion has been traditionally used for treating waste streams like municipal sewage sludge, organic fraction of municipal solid waste, livestock manure and industrial wastewater (Li, 2011; Marañón,2012; Hagelqvist, 2013; De la Rubia, 2018; Grosser, 2018). Due to recent interest in alternative energy sources, the process is being widely applied for generation of renewable energy from organic residues and energy crops (Weiland, 2003; Corneli, 2016; Wu, 2019). Biogas can be utilized on-site, as fuel for the generation of thermal and electrical energy, or it can be upgraded to renewable 
natural gas (RNG) by removing carbon dioxide and other contaminants then compressed and either fed into the natural gas pipeline or used as a vehicular fuel. Recently USEPA has approved RNG as cellulosic biofuel (equivalent to D-3 Renewable Fuel Standards) if produced from organic wastes and byproducts and used as a vehicular fuel.

The performance of anaerobic digesters is characterized by the methane production rate, which is a product of biogas flow rate (BFR) and methane composition. The methane content also influences the energy content of biogas. Various operating conditions like feed rate, hydraulic and solids retention time, temperature, alkalinity, pH, and feed quality can affect methane production rate (Horiuchi, 2002; Bolzonella,2005; Kim, 2006; Nagao, 2012). Changes in these conditions may adversely affect the process, and corrective actions need to be taken to assist in process recovery. For example, a feed overload can cause $\mathrm{pH}$ to drop, increasing production of carbon dioxide, thereby lowering the methane content of biogas (Khanal,2004; Liu, 2008). Toxins in feed can inhibit microbial populations and lower biogas and methane production rate. On-line process control and optimization techniques to reject disturbances, usually monitor methane production rate (or methane composition) as a measured variable (Pullammanappallil, 1991,1998; Chynoweth, 1994; Polag, 2015; Lara-Cisneros, 2015). Therefore, it is essential to monitor in real-time, on-line digester methane concentration and BFR.

Methane content can be measured off-line using an infrared spectroscope (Kosterev, 1999; Nelson, 2004), gas chromatography (GC) (Buxy, 2012; Krause, 2018), or a mass spectrometer (Chupka, 1968; Fisher, 2006). These instruments can be adapted for on-line measurements as well. However, the costs can be prohibitive. For example, a GC for off-line measurement may cost as much as US\$30,000. Several portable devices are currently available for on-line methane measurement. These include Guardian (Edinburgh Instruments Ltd, Livingston, UK), GEM 2000 (Geotech Environmental Equipment Inc, Denver, Colorado, USA), SKZ 1050B (SKZ Industrial Co., Limited, Shangdong, CHINA), and Dräger X-am® 5600 infrared (Draeger Safety, Inc., Pittsburgh, PA, USA). These instruments are fitted with a pump to collect a sample of biogas for analysis connecting to the pipe carrying biogas from the digesters. Some of these devices can be interfaced to a computer for data logging. Usually, large sample volumes are required so that these instruments can be used only on a large scale anaerobic digester. The cost ranges from US $\$ 1,500$ for the SKZ 1050B to US $\$ 12,000$ for GEM 2000. The methane production rate could be determined by measuring the BFR and along with methane content. For large scale operations with high flow rates, the BFR is usually measured with mass flow meters (Alicat Scientific, Inc., Tucson, AZ, USA) and ultrasonic flow sensors (BW Technologies Ltd, Calgary, Canada). BFR from laboratory-scale anaerobic digesters is usually low, especially during the startup phase while the flow rate may be less than 0.5 liters per day. Mass flow meters, like Alicat, can measure flow rates as low as $720 \mathrm{ml}$ per day, can be costly. Usually, liquid displacement devices are used to measure low BFR. These designs include the wet gas meter (Shinagawa Corporation, Tokyo, Japan), U-tube manometer-type devices equipped with optical sensors (Liu, 2006) and float switches (Koppar, 2008). In these devices, biogas is allowed to accumulate to a set volume (or pressure) before being released by tipping the chamber (in a wet tip gas meter) or through a solenoid valve in U-tube devices. When biogas is released, a counter records the event and/or a signal is sent to a data logger. The number of such count or signal multiply the gas volume released over a defined time-interval yield the BFR.

With open-source Arduino Uno microcontrollers and associated sensors, it is possible to develop inexpensive devices and controllers for various applications. Previously the authors developed and tested an Arduinobased device for off-line measurement of methane content in gas samples (Yang, 2019). The key component of this device was an inexpensive MQ-4 (Hanwei Electronics Group Corporation, Zhengzhou, China; MQ4 sensor technical data, 2017) hydrocarbon sensor. This sensor, along with another BME-280 which is an integrated pressure, temperature and humidity sensor (manufactured by Bosch Sensortec, Mansfield, Texas, USA), was placed inside a chamber. This methane-sensing device chamber, a $405 \mathrm{ml}$ air-tight mason jar with a screw lid, was modified to provide appropriate environmental conditions for optimal sensor response. The sensors were interfaced to an Arduino microcontroller. Samples were manually withdrawn from the anaerobic digesters and injected into the chamber to measure methane content. After each injection, the lid of the mason jar was opened to evacuate the chamber and then tightly closed before injecting the next sample. 
By comparing with GC measurements, it was shown that this device could accurately $(+/-0.85 \%)$ measure the methane content of biogas samples from an anaerobic digester. The device was assembled in-house for a cost of US $\$ 36$, which is a fraction of the cost of commercially available instruments.

In this paper, we report the modifications of the off-line, MQ-4/BME-280/Arduino-based device described above for on-line, automatic and real-time measurements of methane content in biogas. As all measurement steps were done automatically, it was necessary to develop protocols, methods and ascertain optimal durations for the following tasks: preheating the sensors, introducing sample gas, taking measurements, and evacuating the chamber. The complex modified device was connected to a laboratory-scale fluidized bed digester. Methane content automatically measured by the device was compared to off-line GC measurements. Additionally, we replicated the operation of a manometer-type device for measuring the biogas flow rate by using a BME-280 sensor interfaced to an Arduino Uno.

\section{MATERIALS AND METHODS}

Figure 1 shows a schematic diagram of the laboratory-scale fluidized bed anaerobic digester (block c) connected to the on-line methane content measurement devices (block a) and the biogas volumetric flowmeter (block b). The construction and operation of the on-line measurement devices are described below.

\subsection{On-line Methane Composition Measurement Device.}

The on-line methane composition measurement devices are made up of the methane-sensing device chamber (MSDC), air-drying chamber (ADC), air pump, two-way valves B, C, D actuated by solid-state relays, two Arduino microcontroller boards (1 and 2), and an SD card for storing and retrieval of data. The MSDC was a $600 \mathrm{ml}$ screw-top glass mason jar in which an MQ-4 methane sensor and a BME-280 (pressure, temperature and humidity) sensor were placed. The jar was partly filled with drierite to dry gases held in the jar so as to prevent moisture interfering with the response of the MQ-4 sensor (Yang, 2019). The lid of this jar was equipped with three ports, the first one to introduce gases, the second to evacuate the gases and the third one to pass wires that transmit signals from the sensors. Two-way valve $\mathrm{B}$ regulated the inflow of biogas sample and two-way valve $\mathrm{C}$ regulated the outflow of gases from the MSDC. The ADC was a $900 \mathrm{ml}$ glass mason jar with a screw-top lid. Three-quarters of this jar was filled with drierite to dry the air before it flowed into the MSDC. The lid of this mason jar was fitted with two ports, an inlet and outlet for the air. Outlet air flow was controlled by two-way valve D. An air pump was connected to the inlet port. Arduino 1 was used to acquire data from MQ-4 and BME-280 sensors from the MSDC, and Arduino 2 was used to turn on and off the solid-state relays that operated the air pump and the two-way valves A, B, C, and D. The inlet and outlet ports for both mason jars were nylon adapters passing tightly through holes drilled on the screw-cap lids and were connected to Tygon tubing on the outside. The hole for the wire port was drilled to securely hold a $1 / 8$ " male, brass, hex nipple fitting through which the electrical wires were passed. One-minute instant mix epoxy (Loctite, USA) was used to seal the gaps between lid and nylon adapters, between the lid and brass fitting, and within the brass fitting to seal gaps between wires.

Biogas from the anaerobic digester normally flows into the biogas chamber through the valve A as it is usually open, and valves $\mathrm{B}$ and $\mathrm{C}$ are normally closed. In this state, biogas is metered by the biogas volumetric flowmeter device, as discussed in section 2.2 below. Measurement of the methane composition in biogas is carried out in three steps: (1) preparation of the sensors in the MSDC (2) gas sample injection and methane content measurement, and (3) ventilation of the MSDC.

The first step involves preheating the MQ-4 sensor and absorption of moisture in the MSDC. The MQ-4 methane sensor requires preheating and low humidity for a linear response to methane content. The MSDC is turned on 60 minutes prior to sample injection to allow sufficient time for preheating the sensor. After this, the following processes are initiated for step 2. Valve A is closed for two minutes and the biogas is allowed to build up pressure in the headspace of the anaerobic digester. Valve B is momentarily opened to 
divert gas flow to the MSDC, thus automatically injecting a sample into the MSDC. After many trials, it was determined that valve B needs to be opened for only 500 milliseconds to allow enough gas sample to flow into the MSDC for measurement. Right after the valve B is closed, and valve A is opened so that, as before, the biogas continues to flow into the flow meter for recording BFR. The signals from the BME- 280 and MQ-4 sensors are collected every five seconds. The signal values are averaged over five minutes time intervals and saved on the SD card. Soon after the injection of a biogas sample, the humidity of the chamber increases and then begins to decrease as moisture is absorbed by drierite. Following Yang et al. (Yang, 2019), MQ-4 signals collected after the humidity drops below $1 \%$ are used to calculate methane content. From many trials by injecting different volumes of biogas samples, the time required for humidity to drop below $1 \%$ and the MQ-4 sensor output signal to stabilize was determined to be around 35 minutes. Subsequently, the methane composition is monitored for an additional 25 minutes, and the average of the data collected during this interval is used for methane composition calculations. The following equations are used to calculate the volume of the injected sample:

$P=P_{2}-P_{1}(1)$

$n_{\text {inject }}=\frac{\Delta \Pi \times V_{\text {sn } \alpha \mu \beta \varepsilon \rho}}{}$

englishR $\times T(2)$

$V_{\text {inject }}=\frac{n_{\text {inject }} \times R \times T}{P_{2}}(3)$

$M_{\text {inject }}=\frac{\left(M_{\text {chamber }}-M_{\text {initial }}\right) \times V_{\text {chamber }}}{V_{\text {inject }}}(4)$

where

$P_{1}$ is pressure in the MSDC before opening valve $\mathrm{B}, \mathrm{kPa}$

$P_{2}$ is the average pressure in the MSDC between 35 and 60 minutes after injection of sample, $\mathrm{kPa}$

$V_{\text {chamber }}=$ volume of the MSDC, $\mathrm{ml}$

$R=$ universal gas constant $=8314 \mathrm{ml} \mathrm{kPa} / \mathrm{K} / \mathrm{mol}$

$T=$ average temperature in $\mathrm{K}$, in the MSDC between 35 and 60 minutes after sample injection

$V_{\text {inject }}=$ volume of gas injected by diverting gas flow into the MSDC, $\mathrm{ml}$

$M_{\text {inject }}=$ methane content (by volume) of the injected gas sample

$M_{\text {chamber }}=$ methane content (by volume) in the MSDC after injection of sample

$M_{\text {initial }}=$ initial methane content (by volume) in the MSDC before sample injection

$M_{\text {initial }}, M_{\text {chamber }}$ are calculated from average MQ-4 sensor signal values as outlined (Yang, 2019).

After analysis, the MSDC is evacuated (step 3) using the following procedures. Valves C and D are opened, and the air pump is turned on for 8 to 10 minutes which is the time required to dilute the methane content in the MSDC to less than $0.2 \%$. The air is pre-dried by passing through the ADC and then flows into the MSDC, flushing the sample gas out. The pre-dried air can reduce the preparation time. Two seconds after turning off the air pump, valves C and D are closed, thus first step preparation for MSDC started.

\subsection{On-line Biogas Volumetric Flowmeter Device.}

The on-line biogas volumetric flowmeter device is made up of a biogas chamber ( $405 \mathrm{ml}$ glass mason jar) and a BME-280 sensor. The lid of this jar was equipped with two ports, the first one to introduce and evacuate biogas (called the biogas chamber port) and the second to pass wires that transmit signals from the sensor. One end of a three-way solenoid valve was connected to the biogas chamber port and the other end to the anaerobic digester through valve A. Under regular operations, this path is open. The other opening of the 
three-way valve serves as a vent port which is normally closed. When valve $\mathrm{A}$ is also open, gas from anaerobic digester fills the biogas chamber (BC). When a preset pressure increase occurs, two events happen: (A) the three-way valve closes the port connected to the anaerobic digester and opens the vent port evacuating the gas from the $\mathrm{BC}$ which resets the chamber to atmospheric pressure (B) a time-stamped signal is sent to Arduino 1. Then the vent port remained open for a three-second duration. A ten-millisecond delay was introduced right after the vent closed, the port connecting to the anaerobic digester opens up and biogas continues to fill the BC. The number of venting signals sent to Arduino 1 between two on-line methane composition measurements is counted. The BFR during this interval is the number of signals multiplied by the volume of biogas that triggered one ventilation event. The BME-280 sensor provides values of pressure, temperature and relative humidity in the BC. The sensor is sampled every five seconds and values collected over 30 seconds (six data points) are averaged and stored. The averaged value is replaced every subsequent 30 seconds. The stored value of pressure (which is the current value) is used to calculate $\Delta \mathrm{P}_{\mathrm{bg}}\left(=\mathrm{P}_{\text {current }}\right.$ $\mathrm{P}_{\text {initial }}$ ), where $\mathrm{P}_{\text {initial }}$ is the pressure in the $\mathrm{BC}$ immediately before the port to the digester is opened (soon after ventilation of the $\mathrm{BC})$. When $\Delta \Pi_{\beta \gamma}$ is equal to or greater than the preset value $(15 \mathrm{kPa})$, the port connected to the digester is closed and the vent port opens up. The stored values of relative humidity and temperature are used to calculate the volume of dry biogas at standard temperature and pressure that is released. The partial pressure of water vapor $\left(p_{w}\right)$ in the gas released is calculated using the relative humidity measured by the BME-280 as follows:

$p_{w}=\frac{\Phi}{100} \times p_{\mathrm{ws}}(5)$

where

$\Phi=$ relative humidity (\%)

$\mathrm{p}_{\mathrm{ws}}=$ saturation vapor pressure at the temperature of the $\mathrm{BC}(\mathrm{kPa})$

The temperature of biogas in the $\mathrm{BC}$ should range between room temperature $\left(22^{\circ} \mathrm{C}\right)$ and digester operating temperature $\left(55^{\circ} \mathrm{C}\right)$. A second order polynomial is used to calculate $\mathrm{p}_{\mathrm{ws}}$ between temperature of $21^{\circ} \mathrm{C}$ and $55{ }^{\circ} \mathrm{C}$ :

$p_{\mathrm{ws}}=0.0085 \Theta_{\mathrm{bg}}^{2}+0.2678 \Theta_{\mathrm{bg}}+4.4792$ for $21^{\circ} \mathrm{C} \leq \Theta_{\mathrm{bg}} \leq 55^{\circ} \mathrm{C}$ (6)

where $\Theta_{\mathrm{bg}}=$ temperature of biogas in the $\mathrm{BC}\left({ }^{\circ} \mathrm{C}\right)$

The volume of dry biogas evacuated at standard temperature and pressure is calculated as follows:

$V_{\mathrm{bg}}=\frac{\left(P_{\mathrm{bg}}-p_{w}\right) \times V_{\mathrm{bg} \text { chamber }} \times V_{\mathrm{mv}}}{R \times T_{\mathrm{bg}}}(7)$

Where $\mathrm{V}_{\mathrm{bg}}$ chamber $=$ volume of $\mathrm{BC}(405 \mathrm{ml})$

$\mathrm{R}=$ gas constant $=8314 \mathrm{ml} \mathrm{kPa} / \mathrm{K} / \mathrm{mol}$

$\mathrm{T}_{\mathrm{bg}}=$ temperature of biogas in $\mathrm{BC}(\mathrm{K})=\Theta_{\mathrm{bg}}+273.15$

$\mathrm{V}_{\mathrm{mv}}=$ molar volume of ideal gas at STP $(22.4 \mathrm{~L} / \mathrm{mol})$

Dividing $\mathrm{V}_{\mathrm{mv}}$ by the time interval between two consecutive evacuations yields the volumetric BFR. The methane production rate is the product of BFR multiplied by the methane composition of biogas measured by the on-line sensor. All the steps above to calculate these measurements were fully automated and programmed into the Arduinos.

\subsection{Laboratory-Scale Anaerobic Fluidized Bed Digester (AFBR).}

The AFBR has a working volume of $5.5 \mathrm{~L}$ leaving a headspace of $1.5 \mathrm{~L}$ with six sample ports spaced 4" apart which are used for sample collection, feed input, recirculation and thermocouple access. Commercial prewashed activated carbon particles $(0.5 \mathrm{~mm}$ in diameter) are used as carriers in the AFBR. Fluidization is provided by recirculating the reactor liquid using a peristaltic pump at a flow rate of $10 \mathrm{~L}$ per minute. 
The use of such a high flow rate ensures good mixing in the reactor. Biomass growth was observed on the surface of the activated carbon particles.

A modular data logger, CR10X that is available with a measurement and controller module is used to control the temperature of the reactor (Polematidis, 2010). An on-off protocol was developed using the CR10 software to control the process of heating the reactor liquid to $55 \pm 2{ }^{\circ} \mathrm{C}$. The AFBR was acclimatized to cellulosic ethanol stillage and fed daily. Under normal operating conditions, $200 \mathrm{ml}$ of stillage was fed daily at 11:30 AM using a timer. The timer was used to turn on a peristaltic pump for loading ethanol stillage. The methane measurements made over 23 days are reported here. During this period, to investigate the response of the on-line methane sensor to disturbances, the daily volume of feed was increased to $400 \mathrm{ml}$ on days 1 and 2,600 $\mathrm{ml}$ on day 3 , returned to $200 \mathrm{ml}$ for days 4 to 9 , increased to $800 \mathrm{ml}$ on day 10, further increased to $1200 \mathrm{ml}$ from days 11-16 and brought back to the normal volume of $200 \mathrm{ml}$ from day $17 \mathrm{on}$.

\section{4 Devices Validation Tests.}

Several tests were carried out to validate the function of the devices. After assembly, the devices were first checked for gas leakage. $24 \mathrm{ml}$ standard biogas (Airgas, Tampa, Florida, USA) containing $60 \%$ methane and $40 \%$ carbon dioxide, was introduced into both MSDC and BC, and the pressure and temperature of the chambers were monitored overnight. In the next test, four biogas samples from the AFBR were injected into the MSDC consecutively. Signals from the on-line methane content measurement devices were monitored for 2 hours after each injection. Steps of "Methane sensor response," "Sample venting," and "Preheating sensors" were determined from these injections and the same as the duration. Before a sample was automatically introduced into the MSDC, a $1 \mathrm{ml}$ sample was withdrawn and injected into a GC. After three days of testing, the on-line devices were programmed to measure the methane content of biogas automatically every three hours. The methane content of gas samples was also measured using a GC. The measurement made on the off-line GC was compared with the methane content measurement by the sensor.

\section{5 Gas Chromatograph (GC) for Methane Composition Measurement.}

A thermal conductivity detector equipped GC (Gow-Mac series 580, Bethlehem, PA, USA) was used to measure methane content of gas samples withdrawn from the headspace of the AFBR. A SUPELCO (SigmaAldrich Corp, St. Louis, MO, USA) analytical column 80/100 HAYESEP Q (9 ft x 1/8-inch,1mmSS) was used in the GC, with helium as a carrier gas. The operating conditions of the GC (Buxy, 2012) were: column temperature $61{ }^{\circ} \mathrm{C}$; detector temperature $152{ }^{\circ} \mathrm{C}$; and injector temperature $81{ }^{\circ} \mathrm{C}$. The sample gas from the AFBR was collected during the daytime, and each time $1 \mathrm{ml}$ sample was withdrawn from the headspace of the reactor and then injected into the GC for methane composition analysis. The sample gas was successively taken every 30 minutes, so the average of the GC measurement was used for comparing with the on-line methane content measurement device. Under normal operating conditions, the sample gas was usually taken between 10:30 AM and 12:00 PM. GC measurements for methane content were taken during the 23 days while the methane content of the AFBR was changed by introducing feed loading changes. The daily loading rate and the corresponding methane content measurements were compared to the data analyzed by on-line methane content measurement device.

\section{RESULTS AND DISCUSSION}

\subsection{Devices leakage test.}

The first step in testing the devices was to check for leakage. The fully assembled devices (three chambers in Figure 1) were tested for leakage. The biogas was introduced into the chambers through valve B, keeping valves $\mathrm{A}$ and $\mathrm{D}$ open, and closed. The pressure, temperature, and relative humidity data were collected for 
twelve hours. The ratio of absolute pressure to absolute temperature was recorded by Aruidno against time and was consistent with a range from 0.3571 to 0.3563 over 12 hours, which indicated minimal leakage.

\subsection{Response of methane sensor to biogas samples.}

Figure 2 shows the responses of the MQ-4 sensor to four consecutive injections of biogas samples from the AFBR. These biogas samples were automatically injected into the MSDC. Each time, the MSDC was taken through the preheat, sample injection and measurement, and sample venting steps as described above. As the methane production rate from the anaerobic digester fluctuated, the buildup of the pressure in the headspace of the digester varied when valve A was closed for two minutes. Consequently, different amount of biogas was introduced into the MSDC when valve B was opened for 500 milliseconds. Sample volumes introduced into the MSDC were $6.42,7.52,7.47$, and $6.99 \mathrm{ml}$, respectively. These volumes were calculated automatically by the Arduino program using equations 1,2 and 3. After each biogas sample injection, the methane content value increased rapidly in the first 5 minutes, then decreased and stabilized within the next 60 minutes as the sample completely distributed within the MSDC. The methane concentrations measured between 35 and 55 minutes, sampled every five seconds, were averaged in a five-minute interval to obtain the $M_{\text {chamber }}$ value. The mean and standard deviation (expressed as \% of mean) from the four consecutive biogas samples shown in Figure 2 were $1.252 \pm 0.004 \%$ (for $6.42 \mathrm{ml}$ injection), $1.490 \pm 0.002 \%(7.52 \mathrm{ml}), 1.529 \pm 0.006 \%$ (7.47 $\mathrm{ml})$ and $1.450 \pm 0.001 \%(6.99 \mathrm{ml})$. The average methane concentration before injection of the four samples, $M_{\text {initial }}$, were $0.16 \pm 0.000 \%, 0.15 \pm 0.000 \%, 0.16 \pm 0.000 \%$ and $0.16 \pm 0.000 \%$. Using the equation 5 , the methane concentration of injected biogas was calculated as $78.98 \% \pm 0.26 \%$ (6.42 ml), $80.28 \pm 0.13 \%$ (7.52 $\mathrm{ml}), 82.95 \pm 0.34 \%(7.47 \mathrm{ml})$ and $83.97 \pm 0.06 \%(6.99 \mathrm{ml})$. From GC measurements, the average methane content of biogas samples collected from headspace of the digester immediately after valve B was closed prior to the four injections were $81.22 \% \pm 0.33 \%$.

\subsection{Automatic on-line measurements of biogas samples.}

The composition of biogas produced from the AFBR was monitored over 23 days. During this period, the volume of daily feed loading was changed. Figure 3-1 shows the volume of cellulosic ethanol stillage that was loaded into the AFBR every day. Figure 3-2 shows the response, in terms of volumetric methane production rate per hour. Figure 3-3 shows the methane composition measured by the on-line sensor and compares it to the value measured by off-line GC. The on-line measurement device measures the methane composition in biogas every 3 hours. The mean and standard deviation of the methane composition in the AFBR headspace is shown in figure 3-3. The methane measurement from the on-line measurement device shows a pattern similar to that of the GC measurements.

A challenge for measuring the methane percentage for the AFBR on-line is that the sampling period should be sufficiently short to track responses to disturbances. For instance, overloading feed into the digester can cause a drop in $\mathrm{pH}$ due to volatile organic acid accumulation and decrease the methane production rate. $\mathrm{pH}$ fluctuations may also affect the carbon dioxide concentration of the gas phase, which in turn affects the methane composition. The operation of the digester with these disturbances is shown in Figure 3. In the first two days, the methane concentration started to drop when $400 \mathrm{ml}$ of feed was added daily. On day three, $600 \mathrm{ml}$ of feed was loaded into the digester. This caused a further drop in methane concentration which was tracked by the on-line sensor. Then normal loading of $200 \mathrm{ml}$ per day was resumed over the next six days. Methane concentration increased as observed from GC and on-line measurements. On day 10, feed of $800 \mathrm{ml}$ was loaded followed by $1200 \mathrm{ml}$ of feed from days 11 to 16 . The methane concentration dropped until day 13 before beginning to increase as the digester became acclimatized to $1200 \mathrm{ml}$ of daily feed. The on-line measurements followed this trend. The methane concentration fluctuated around a value of $75.5 \%$ after the daily feed was decreased to the normal value of $200 \mathrm{ml}$ from day 17 on. By day 23, the amplitude of these fluctuations shows a dampening behavior which was also tracked nicely by the on-line sensor measurements. 


\subsection{Average absolute difference of the on-line measurements.}

As Figure 3-3 shows, the GC measurements were not taken at the same frequency as the on-line measurements. In addition, the AFBR was operating under unsteady state conditions. So a procedure was devised to compare GC values with the on-line measurements. For a measurement made on the GC at a particular time, all on-line measurements done over a time period $\Delta t$ before and after the GC measurement were averaged and compared. Longer $\Delta \mathrm{t}$ values would include dynamic variation, whereas shorter $\Delta \mathrm{t}$ would not include many on-line measurements. It was found that a $\Delta t$ of three hours minimized dynamic variations and provided at least six data points for each GC measurement. The comparison made by averaging on-line data collected three hours before a GC measurement and three hours after GC measurement is shown in Figure 4.

An average absolute difference between GC measurements and averaged on-line measurements was calculated as follows. The absolute difference between GC measurement and averaged on-line measurement was calculated. This calculation was performed for all 80 data points shown in Figure 4. The average of these values was termed as average absolute difference and was $0.81 \pm 0.54 \%$.

\subsection{Cost of on-line measurement system}

The cost of the components required for converting the off-line methane measurement device to an automated real-time on-line measurement system is listed in Table 1. The total cost of the on-line system amounted to US $\$ 138.36$, including the primary components of assembled methane-sensing device chamber, assembled air-drying chamber, assembled biogas chamber, and Arduino microcontrollers. The cost of this system is only a fraction of the cost of commercial devices. In addition, the methane composition measured by the on-line sensor can be displayed using an LED interfaced to the Arduino Uno. The cost of such an LED display is $\$ 7$.

Table 1. Cost of on-line methane system

\begin{tabular}{ll}
\hline Components & Price (US \$) \\
\hline Assembled methane-sensing device chamber (with & 36.61 \\
BME-280, MQ-4 sensors and drierite) (Yang, 2019) & \\
2-way valve (4 unit) & 39.99 \\
3-way valve (1 unit) & 12.99 \\
Air pump & 6.99 \\
Second Micro-Computer (Arduino Uno) & 10.90 \\
Wire and tubing & 1.00 \\
Assembled drying chamber (with drierite) & 10.90 \\
Assembled biogas chamber (with BME-280 sensor) & 14.99 \\
SD card & 3.99 \\
TOTAL & 138.36 \\
\hline
\end{tabular}

\section{CONCLUSIONS}

An inexpensive system was assembled and successfully tested for automatic, real-time, on-line measurement of the methane content of biogas from a laboratory-scale anaerobic digester. The on-line system is capable of taking measurements at a minimum sampling interval of three hours, which includes venting biogas residue, sensors preparation, drying chamber and stabilization of the sensor signals. This on-line methane measurement device can be easily integrated with a biogas volumetric flowmeter device to calculate the methane production rate from a digester. The on-line measurement system fills a much-needed void for monitoring biogas produced from laboratory-scale anaerobic digesters as commercial systems require large 
gas volumes.

\section{ACKNOWLEDGEMENTS}

This work was funded by US-Israel Binational Agricultural Research and Development (BARD) [award number US-4877-15]. This work was also supported by the US Department of Energy's Office of Energy Efficiency and Renewable Energy, Bioenergy Technologies Office and sponsored by the US Department of Energy's International Affairs [award number, DEPI0000031].

\section{REFERENCES}

Bolzonella, D., Pavan, P., Battistoni, P., \& Cecchi, F. (2005). Mesophilic anaerobic digestion of waste activated sludge: influence of the solid retention time in the wastewater treatment process. Process biochemistry, 40(3-4), 1453-1460.

Buxy, S., Diltz, R., \& Pullammanappallil, P. (2012). Biogasification of marine algae Nannochloropsis oculata. Materials Challenges in Alternative and Renewable Energy II: Ceramic Transactions, 59-67.

Chupka, W. A. (1968). Mass-Spectrometric Study of the Photoionization of Methane. The Journal of Chemical Physics, 48(5), 2337-2341.

Chynoweth, D. P., Svoronos, S. A., Lyberatos, G., Harman, J. L., Pullammanappallil, P., Owens, J. M., \& Peck, M. J. (1994). Real-time expert system control of anaerobic digestion. Water Science and Technology, 30(12), 21-30.

Corneli, E., Dragoni, F., Adessi, A., De Philippis, R., Bonari, E., \& Ragaglini, G. (2016). Energy conversion of biomass crops and agroindustrial residues by combined biohydrogen/biomethane system and anaerobic digestion. Bioresource technology, 211, 509-518.

De la Rubia, M. A., Villamil, J. A., Rodriguez, J. J., Borja, R., \& Mohedano, A. F. (2018). Mesophilic anaerobic co-digestion of the organic fraction of municipal solid waste with the liquid fraction from hydrothermal carbonization of sewage sludge. Waste Management, 76, 315-322.

Fisher, R., Lowry, D., Wilkin, O., Sriskantharajah, S., \& Nisbet, E. G. (2006). High-precision, automated stable isotope analysis of atmospheric methane and carbon dioxide using continuous-flow isotope-ratio mass spectrometry. Rapid Communications in Mass Spectrometry: An International Journal Devoted to the Rapid Dissemination of Up-to-the-Minute Research in Mass Spectrometry, 20(2), 200-208.

Hagelqvist, A. (2013). Batchwise mesophilic anaerobic co-digestion of secondary sludge from pulp and paper industry and municipal sewage sludge. Waste management, 33(4), 820-824.

Horiuchi, J. I., Shimizu, T., Tada, K., Kanno, T., \& Kobayashi, M. (2002). Selective production of organic acids in anaerobic acid reactor by $\mathrm{pH}$ control. Bioresource technology, 82(3), 209-213.

Grosser, A., \& Neczaj, E. (2018). Sewage sludge and fat rich materials co-digestion-Performance and energy potential. Journal of Cleaner Production, 198, 1076-1089.

Khanal, S. K., Chen, W. H., Li, L., \& Sung, S. (2004). Biological hydrogen production: effects of pH and intermediate products. International journal of hydrogen energy, 29(11), 1123-1131.

Kim, J. K., Oh, B. R., Chun, Y. N., \& Kim, S. W. (2006). Effects of temperature and hydraulic retention time on anaerobic digestion of food waste. Journal of Bioscience and bioengineering, 102(4), 328-332.

Koppar, A., \& Pullammanappallil, P. (2008). Single-stage, batch, leach-bed, thermophilic anaerobic digestion of spent sugar beet pulp. Bioresource Technology, 99(8), 2831-2839. 
Kosterev, A. A., Curl, R. F., Tittel, F. K., Gmachl, C., Capasso, F., Sivco, D. L., .. \& Cho, A. Y. (1999). Methane concentration and isotopic composition measurements with a mid-infrared quantum-cascade laser. Optics letters, 24(23), 1762-1764.

Krause, M. J., Chickering, G. W., Townsend, T. G., \& Pullammanappallil, P. (2018). Effects of temperature and particle size on the biochemical methane potential of municipal solid waste components. Waste Management, 71, 25-30.

Lara-Cisneros, G., Aguilar-López, R., \& Femat, R. (2015). On the dynamic optimization of methane production in anaerobic digestion via extremum-seeking control approach. Computers \& Chemical Engineering, $75,49-59$.

Li, Y., Park, S. Y., \& Zhu, J. (2011). Solid-state anaerobic digestion for methane production from organic waste. Renewable and sustainable energy reviews, 15(1), 821-826.

Liu, D., Zeng, R. J., \& Angelidaki, I. (2008). Effects of pH and hydraulic retention time on hydrogen production versus methanogenesis during anaerobic fermentation of organic household solid waste under extreme-thermophilic temperature (70degC). Biotechnology and bioengineering, 100(6), 1108-1114.

Liu, J., Olsson, G., \& Mattiasson, B. (2004). A volumetric meter for monitoring of low gas flow rate from laboratory-scale biogas reactors. Sensors and Actuators B: Chemical, 97(2-3), 369-372.

Maranon, E., Castrillon, L., Quiroga, G., Fernandez-Nava, Y., Gomez, L., \& Garcia, M. M. (2012). Codigestion of cattle manure with food waste and sludge to increase biogas production. Waste management, $32(10), 1821-1825$.

Nagao, N., Tajima, N., Kawai, M., Niwa, C., Kurosawa, N., Matsuyama, T., .. \& \& Toda, T. (2012). Maximum organic loading rate for the single-stage wet anaerobic digestion of food waste. Bioresource Technology, 118, 210-218.

Nelson, D. D., McManus, B., Urbanski, S., Herndon, S., \& Zahniser, M. S. (2004). High precision measurements of atmospheric nitrous oxide and methane using thermoelectrically cooled mid-infrared quantum cascade lasers and detectors. Spectrochimica Acta Part A: Molecular and Biomolecular Spectroscopy, 60(14), 3325-3335.

Polag, D., May, T., Muller, L., Konig, H., Jacobi, F., Laukenmann, S., \& Keppler, F. (2015). On-line monitoring of stable carbon isotopes of methane in anaerobic digestion as a new tool for early warning of process instability. Bioresource technology, 197, 161-170.

Polematidis, I., Koppar, A., \& Pullammanappallil, P. (2010). Biogasification potential of desugarized molasses from Sugarbeet processing plants. Journal of Sugar Beet Research, 47(3/4), 89-104.

Pullammanappallil, P., Harmon, J., Chynoweth, D. P., Lyberatos, G., \& Svoronos, S. A. (1991). Avoiding digester imbalance through real-time expert system control of dilution rate. Applied biochemistry and biotechnology, 28(1), 33-42.

Pullammanappallil, P. C., Svoronos, S. A., Chynoweth, D. P., \& Lyberatos, G. (1998). Expert system for control of anaerobic digesters. Biotechnology and bioengineering, 58(1), 13-22.

Weiland, P. (2003). Production and energetic use of biogas from energy crops and wastes in Germany. Applied biochemistry and biotechnology, 109(1-3), 263-274.

Wu, N., Moreira, C., Zhang, Y., Doan, N., Yang, S., Phlips, E., .. \& Pullammanappallil, P. (2019). Techno-economic analysis of biogas production from microalgae through anaerobic digestion. In Biogas. IntechOpen.

Yang, S., Liu, Y., Wu, N., Zhang, Y., Svoronos, S., \& Pullammanappallil, P. (2019). Low-cost, Arduinobased, portable device for measurement of methane composition in biogas. Renewable energy, 138, 224-229. 


\section{Figures Captions}

Figure 1. Schematic diagram of laboratory-scale fluidized bed reactor (block c) with on-line measurement of methane composition (block a) and BFR (block b). (1) $405 \mathrm{ml}$ Methane sensor device chamber, (2) Sensors (BME-280 and MQ-4), (3) Drierite, (4) Screw-capped lid with O-ring, (5 and 6) Arduino data loggers, (7) Air pump, (8, 9, 10 and 12) Arduino controlled 2-way valves, (11) Sensor (BME-280), (13) 405 ml biogas Chamber, (14) Anaerobic Fluidized Bed Reactor (15) SD card

Figure 2. Response of on-line methane sensor to biogas samples automatically injected into MSDC device chamber. (A) Preheat (B) Methane measurement (C) Vent

Figure 3. AFBR operation and response. (4-1) The volume of cellulosic ethanol stillage fed daily, (4-2) Biogas production rate and (4-3) Methane composition of biogas measured by on-line sensor and GC.

Figure 4. On-line methane measurements by sensor, averaged over a +-3 hour time interval within an off-line GC measurement compared to the average off-line GC measurement.

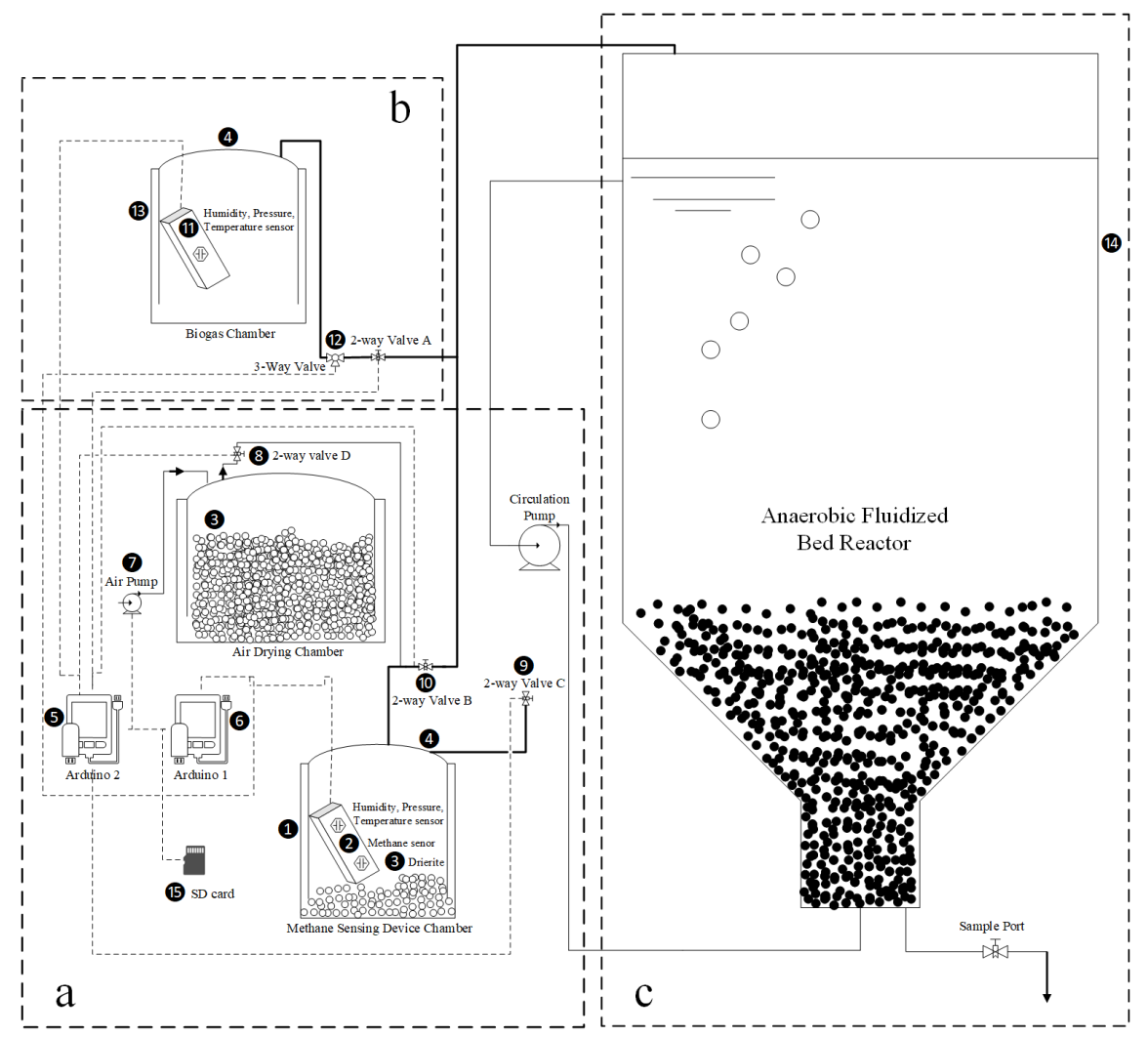



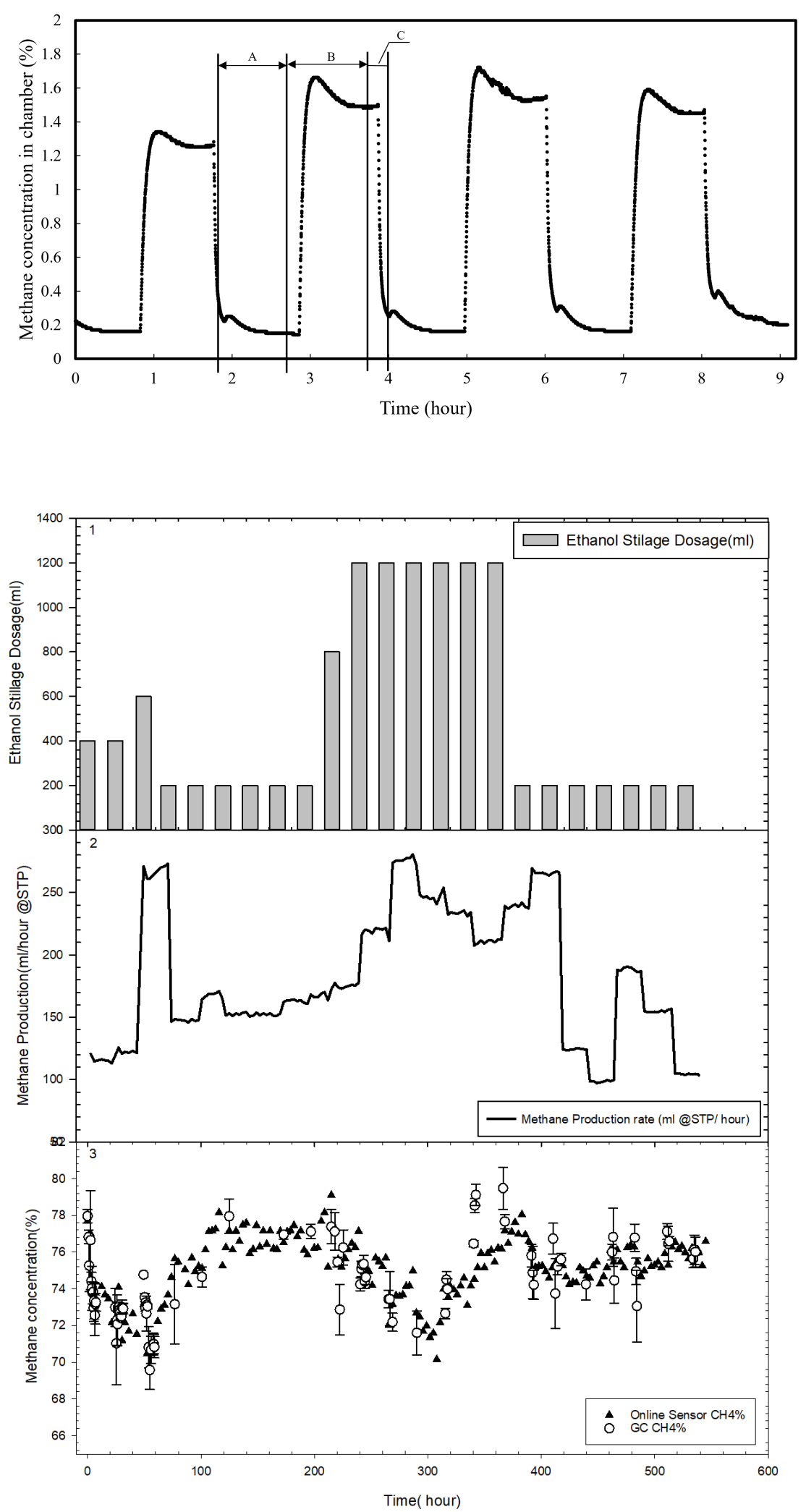


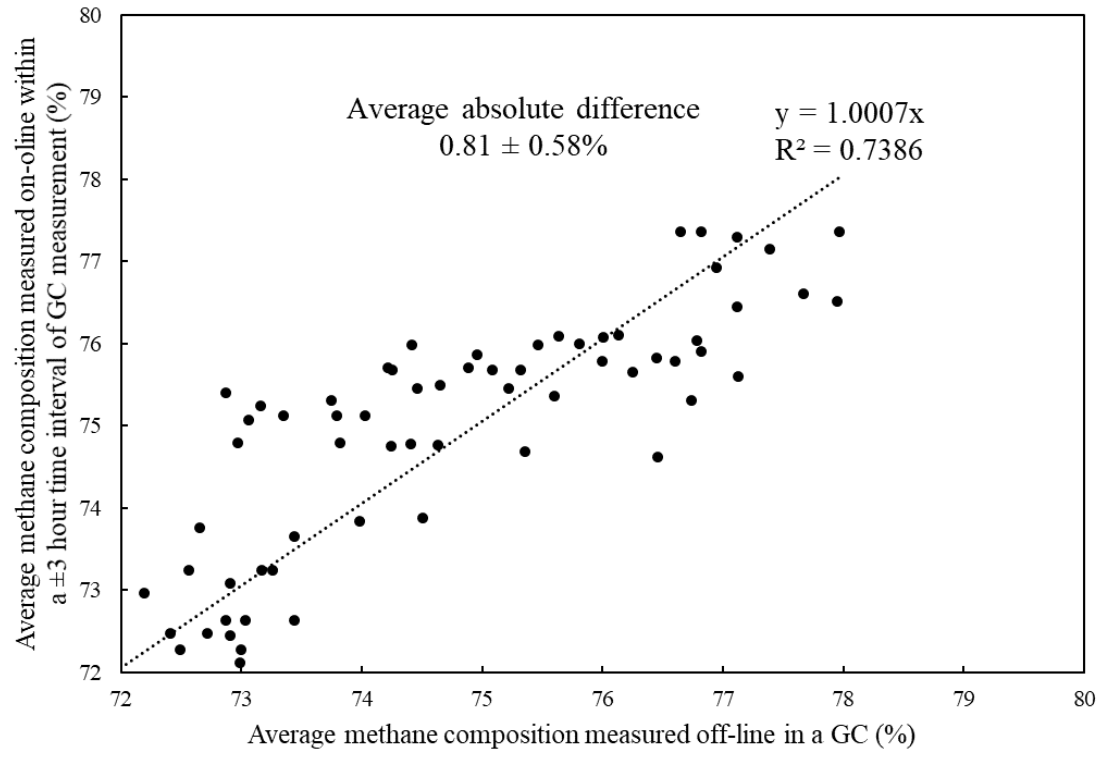

